\title{
Suplementos Jornalísticos e Universidade: Informação ou Imagem
}

\author{
Sibila Rocha ${ }^{1}$ \\ Unifra \\ sibila@unifra.br
}

\begin{abstract}
Resumo: As universidades buscam visibilidade na esfera pública através de diferentes ordens. Este artigo é um recorte da tese, A Universidade na Mídia. A fala acadêmica na voz do jornal, finalizada em março de 2004, no PPG em Ciências da Comunicação, da UNISINOS/RS, onde foram selecionadas três universidades gaúchas - Unisinos, Ulbra e PUC/RS - pesquisadas em três conjuntos de discursividades: os suplementos semanais, do jornal ZH/RS, matérias interpretativas veiculadas nos jornais $Z H$ e Correio do Povo e reportagens gerais editadas nos jornais referidos. Neste artigo, apresentamos os conjuntos de discursos analisados nos suplementos jornalísticos editados no $\mathrm{ZH}$, pois traduzem uma tendência no mercado do jornalismo e, por isso, apontam para o modo como as instituições universitárias buscam legitimidade de seu mundo através de discursividades jornalísticas.
\end{abstract}

Palavras Chaves: Universidade - Suplementos - Discurso

Abstract: The university discussed in the writeen media from the enunciated construction that leads to image of the institution.This work is the resdult of a research The University In Media.The Acadmic Speech Through The Newspaper, what selected three universities from Rio Grande do Sul.This universe of research is na example of real relations amog the fields of universities and the medias, from the journalistic news we show, a symbolized universe of the institution that, among other meanings of effects, produce the image of the university.

Key Words: University, Journalism, Speech.

1 Professora da Unifra nos cursos de Jornalismo e Publicidade e Propaganda. Coordenadora do Núcleo de Pesquisas (Nupec). Doutora em Ciências da Comunicação pela Unisinos. 


\section{1 - Introdução}

Os suplementos encartados nos jornais diários abrigam um grupo de notícias que se transformam em jornais à parte, como se fossem anexos do jornal matriz. Trata-se de um produto jornalístico que trabalha com material informativo especializado, que normalmente não conquista espaço nas edições diárias dos veículos. A função do suplemento, portanto, para além da segmentação da informação, é dilatar o significado de realidade, no sentido de ampliar as condições de produção de formas simbólicas de campos sociais que solicitam voz, ou seja, que busquem mais espaço de visibilidade na mídia.

A partir deste contexto, estudamos três suplementos semanais editados no jornal Zero Hora: Eureka!, Vestibular e Vida. Buscamos identificar especificidades, características, pontos em comum e diferenças que apresentam entre si, no que diz respeito às ordens de visibilização do campo da universidade. Para esta análise, acompanhamos, regularmente, trinta edições dos três suplementos, no período de março a setembro de 2003, examinando suas estruturas discursivas, as estratégias de enunciação jornalística até estabelecermos alguns encaminhamentos para o nosso estudo.

Inicialmente propomos o reconhecimento dos três suplementos como um amplo conjunto estrutural, percebidos através de uma abordagem macro analítica. Nesta proposta apresentamos os cadernos dentro de um contexto geral: o que eles têm em comum e quais as diferenças mais significativas. A partir desta contextualização, encaminhamos nossa reflexão para um aprofundamento da análise dos principais elementos textuais e gráficos que compõem a identidade de cada um deles e que funcionam como operadores semânticos do campo da universidade. A partir deste conjunto de material descrito, identificamos categorias de estratégias discursivas que evidenciam a legitimação do campo da universidade.

\section{2 - Semelhanças}

Podemos examinar os suplementos sob a ótica de uma proposta de segmentação da informação de temas de interesse humano bem definidos. O Eureka!, é identificado como um caderno de ciência, voltado para a divulgação científica e anúncios de 
descobertas de repercussão internacional do campo acadêmico procedentes de trabalhos de pesquisas da instituição universidade; o Vestibular concentra seu foco em reportagens de ensino e costumes, referentes ao dia-a-dia e desafios do estudante que aspira uma vaga na universidade. A partir da preparação e experiência desta etapa de vida dos jovens, os assuntos são construídos para dar suporte de conhecimento intelectual e preparo emocional aos vestibulandos, inclusive na orientação das profissões que querem seguir e que estão diretamente ligadas ä escolha do curso que devem ingressar; o Vida é reconhecido como o caderno de saúde e comportamento, que privilegia matérias que anunciam informações a respeito de uma variedade grande de assuntos que têm como eixo temático, a conscientização da importância das pessoas buscarem, através da informação e conhecimento, modos de enfrentar a vida moderna com qualidade física, mental e emocional.

Diferentes nas propostas temáticas, o ritmo semanal dos três suplementos evidencia o primeiro ponto em comum entre eles: a característica de reportagens construtoras de temas, agendando expectativas para fenômenos sociais, sem a preocupação com assuntos restritos, exclusivamente, com a factualidade da realidade. Trabalhando numa outra temporalidade, a semanal, os suplementos, diferente dos jornais diários, podem dirigir o fio do enfoque das matérias, através de um conjunto de operações enunciativas que contêm um trabalho de semantização voltando-se para um contexto que ultrapassa os limites da própria temática do caderno.

Isso não significa afirmar, no entanto, que os temas estejam completamente desvinculados da realidade do dia-a-dia dos acontecimentos. Encontramos nas edições dos três suplementos, pautas elaboradas também a partir de fatos desta atualidade vivenciada no cotidiano da sociedade e, especificamente, do mundo da universidade. O que queremos ressaltar é que o trabalho de angulação e edição das matérias dos encartes refletem diferentes condições de produção jornalística.

São discursividades que coincidem com uma expectativa associada às propostas de informação segmentada. Isto posto, reconhecemos outro aspecto convergente entre os suplementos. Não podemos classificar os textos em conjuntos de rigorosas rubricas 
temáticas. Eles são organizados, sim, a partir de uma identidade do caderno, que dependendo do assunto, solicita uma ou outra rubrica, sempre associada, é claro, as tematizações de suas propostas, embora cada caderno apresente uma ou duas secções fixas.

Já as modalidades de notícia que encontramos nestes conjuntos estruturais dos cadernos revelam padrões de técnica de redação jornalística comum aos três, respeitando diferentes estratégias discursivas. Esta similaridade não é exatamente decorrente das semelhanças entre eles, ou das especificidades de cada um deles, mas sim conseqüência de fazerem parte da mesma empresa jornalística, que apresenta regras claras de estilo jornalístico, através de seu Manual de Redação².

Desta observação, identificamos nos três suplementos matérias construídas a partir das características jornalísticas identificadas como: 1- reportagens informativas acompanhadas de material de pesquisa e documentação; 2 - matérias interpretativas sobre o tema proposto; 3 - matérias didatizadoras e pedagógicas; 4 - matérias que reúnem estas três características juntas; 5 - espaço do leitor; 6 - features 7 - fait-divers, 8 entrevista tipo perfil, e 9 -crônicas ${ }^{3}$.

Além destes modos de noticiabilidade, encontramos algumas especificidades particulares de cada suplemento. Nenhum dos três utiliza-se de um editorial convencional nas edições. No Eureka!, a preferência é uma carta do editor ao leitor; no Vestibular, no lugar do editorial existem várias cartas de leitores endereçadas ao caderno e no Vida, no espaço tradicionalmente ocupado pelo editorial, há dez anos, é publicizada uma crônica de um médico - Moacir Scliar, também escritor e pertencente ao quadro de cronistas do jornal Zero Hora. .

\footnotetext{
${ }^{2}$ Aprofundar o estilo jornalístico encontrado na Zero Hora em Manual de Redação, produzido pelo jornalista Augusto Nunes, L\&PM, Porto Alegre, 1994

${ }^{3}$ Muniz Sodré e Maria Helena Ferrareto (1995) categorizam tipos de notícia. e reportagem basicamente em factuais, históricas e documentadas a partir de técnicas de redação pronunciativa (quando o jornalista interpreta o fato) e denunciativa( quando há elementos de interpretação e denúncia a ao mesmo tempo). Já os conceitos de feature (palavra inglesa que significa "feição fisionômica" designa matérias que não estão vinculadas ao dia de sua ocorrência, podendo ser guardada vários dias que não perde o interesse) e fait-divers (de origem francesa, remete a toda e qualquer matéria que implique rompimento insólito ou extraordinário do curso cotidiano dos acontecimentos) são desta forma definidos no Dicionário de Comunicação .(Rabaça e Barbosa, 1998)
} 
Entretanto, o elo marcante de ligação entre os três cadernos é conseqüência da coleta de dados e utilização das fontes ${ }^{4}$ para a produção das matérias jornalísticas, uma vez que têm a mesma origem - a instituição universidade, mesmo que consultada em diferentes perspectivas. Dito de outra forma, os três cadernos trabalham com o discurso jornalístico relacionado com a divulgação de informações e/ou conhecimentos, seja na área da ciência, ensino ou saúde, publicizados e legitimados a partir da consulta (coleta de dados a partir de uma fonte) de um saber científico.

Desta forma, as fontes consultadas pelos três cadernos são cientistas, pesquisadores, professores universitários, profissionais graduados em áreas do conhecimento, reconhecidamente "especializados" e "credenciados" nos temas abordados. Como o local por excelência que se produz conhecimento e em que o agente social se torna um especialista credenciado em determinada área do conhecimento é a universidade, o campo acadêmico passa a fazer parte do universo dos suplementos, uma vez que é nesta esfera que os cadernos se apóiam para divulgação de suas informações.

A relação forma e conteúdo nos suplementos são características marcantes dos cadernos. O planejamento gráfico, um ponto cuidadosamente construído, se apresenta com elementos visuais que são facilmente identificáveis e que tornam os cadernos, como produtos jornalísticos únicos e personalizados.

Coloridos, impactantes e chamativos, esse conjunto de elementos reunidos nos cadernos revelam zelo no equilíbrio do uso da imagem e da escrita como discursividades que se completam e que isoladamente não apresentam a mesma força editorial.

A partir destas sinalizações, passamos a identificar as diferenças produzidas pelas especificidades de cada um dos cadernos. A começar pelo público alvo diferente, que obviamente, é explicitado na segmentação da informação. Entretanto, é interessante identificar que os três suplementos são endereçados à pessoas que têm em comum o interesse em consumir produtos que divulguem informações e conhecimento respaldados

\footnotetext{
${ }^{4}$ Fonte na cultura jornalística significa a procedência da notícia. Todos os documentos e pessoas de onde um autor de trabalho jornalístico, literário, técnico ou artístico, extrai informações para a sua obra.
} 
por um "saber cientificamente legitimado". Apesar deste traço comum, percebemos a partir das tematizações de cada caderno, destinatários diferentes.

O Eureka! tem como público alvo, um conjunto de pessoas interessadas em aprofundar o conhecimento voltado para o campo acadêmico, que busquem uma informação e/ou conhecimento de caráter universal legitimado por um saber comprovadamente científico.

O Vestibular é dirigido a um público jovem que busca conhecer todas as interfaces do período que antecede ao ingresso na universidade e o Vida é voltado para um público heterogêneo, sem faixa etária definida, mas com curiosidade e necessidade de entender de que modo as informações de especialistas da área da saúde e comportamento podem tornarem-se fontes de conhecimento para melhor enfrentar o dia-a-dia da vida da sociedade moderna.

Destas observações e a partir da leitura das cartas dos leitores enviadas aos três cadernos, entendemos que os leitores destes suplementos são, na maioria, universitários, vestibulandos, professores e um público heterogêneo que reconhece (ou que busca?), na instituição universidade, uma legítima instância geradora de conhecimento ou um diálogo intermediado pelos meios de comunicação social.

\section{3 - Diferenças}

O Eureka! é um suplemento semanal que circula no jornal Zero Hora todas às segundas -feiras, com oito páginas e uma proposta clara: Tematizar o campo científico através da divulgação de pesquisas do campo acadêmico. O resultado é um conjunto de matérias que tem a função de traduzir um discurso científico (especializado e opaco) para um discurso jornalístico, transparente e universalmente compreensível ${ }^{5}$.

\footnotetext{
5 Aprofundar esta questão nos conceitos das funções esotérica e exotérica do discurso na visão de Rodrigues, Adriano.1996,pg126 
O nome Eureka! já produz conotações com o conteúdo editado. A palavra eureca tem origem na descoberta de Arquimedes ${ }^{6}$ e remete as descobertas científicas de difícil solução. Aliás, o ponto de exclamação que acompanha todas as páginas, em todas as edições, pode também estar relacionado ao grito de alegria e euforia de Arquimedes na descoberta efetivada.

O caderno tem como patrocinador âncora a Universidade do Vale dos Sinos e se apresenta ao público como um projeto que envolve a parceria técnica da Universidade e a editoria de suplementos do jornal Zero Hora. A voz do jornal apresenta o Eureka! "como um dos poucos suplementos com essas características existente, hoje, entre os grandes jornais brasileiros" ". No entendimento da Unisinos, o Eureka! é um desafio para o acadêmico "descer de sua torre de marfim e falar e se comunicar com um público diferentes daquele da academia"s.

O conjunto de estratégias que caracteriza o suplemento Eureka! como um produto atraente compreende a fragmentação discursiva dos textos impressos das diferentes áreas da ciência . Estes textos curtos, acompanhados de imagens coloridas, legendas didatizantes e infográficos pedagógicos geram efeitos de sentido de informação dinâmica, acessível, diferente das produzidas em textos científicos que normalmente são longos e compactos.

O Vestibular é um suplemento semanal, que circula no Jornal Zero Hora todas às quartas-feiras, desde 1998. O caderno circula, normalmente, com oito páginas, mas esporadicamente este número aumenta para doze, quando quatro páginas são inseridas no encarte como se fossem, literalmente, integrantes de um livro didático, só que como parte de um jornal. Esse encarte "dentro" do encarte, é destinado a testes de conhecimento das

\footnotetext{
${ }^{6}$ Conta-se que o cientista Arquimedes quando descobriu o por quê que dois corpos que ocupam o mesmo espaço na água, um afunda e outro sobe à superfície estava tomando banho de banheira e saiu nu, pela rua, gritando, eureca!, eureca!, eureca!...

${ }^{7}$ Entrevista de Marcelo Rech, diretor de ZH, divulgada no 31 de marco de 2002, no jornal Zero Hora.

${ }^{8}$ Entrevista do pró-reitor de Ensino e Pesquisa, da Unisinos, padre Pedro Gilberto Gomes (31.05.2002 ZH).
} 
disciplinas elencadas no concurso vestibular já aplicados em universidades gaúchas em provas de anos anteriores, respostas comentadas sobre as questões divulgadas e publicização de conteúdos referentes ao exame-vestibular para dar todas as informações necessárias aos seus leitores.

O caderno é basicamente construído a partir do perfil de um "jornalismo de serviço", com matérias estrategicamente produzidas para dar conta desta proposta, comprometida com seu público. Voltado para um público jovem, o nome do encarte é um chamativo direto, sem ligações semânticas ou remissivas ao assunto. Pelo contrário, Vestibular, sem rodeios, oferta-se como um jornal cúmplice deste período dos jovens. Por isso, o caderno Vestibular, na voz do jornal Zero Hora, se diz leitura obrigatória para quem esta atravessando esta fase de vida.

Todas as universidades do Rio Grande do Sul têm, democraticamente, espaço para divulgar (e anunciar, obviamente), informações a respeito do calendário de vestibular, bem como as propostas de ensino de seus cursos de graduação e outras informações que dizem respeito ao acontecimento vestibular. Diferente do Eureka!, que tem apenas um patrocinador, encontramos no Vestibular mais de um anunciante. A ULBRA (Universidade Luterana do Brasil) é patrocinadora fixa, utiliza-se sempre dos mesmos espaços e tem hegemonia entre outros anunciantes. Estes anunciante esporádicos são na grande maioria, universidades do interior do Rio Grande do Sul ou então locais de espaços de atendimento ao vestibulando, como centros de orientação profissional, por exemplo.

O sistema simbólico composto de manchas, traços, ilustrações e letras no Vestibular é o mesmo na totalidade de suas edições. Este sistema é importante porque através dele que o jornal se faz reconhecido pelo seu leitor, mesmo antes de lê-lo. O Vestibular tem esta marca de individualidade que facilmente se reconhece a que grupo social de leitor se destina. É este sistema simbólico que informa ao usuário da língua que “isto é um jornal” voltado para os vestibulandos.

O conjunto de estratégias que caracteriza o Vestibular como um produto para vestibulandos compreende uma discursividades de matérias produzidas estrategicamente a partir de uma lógica pedagógica que ensina, mostra e facilita o entendimento. 
O Vida é dos três suplementos estudados, o mais antigo editado no jornal Zero Hora. Todos os sábados, ele circula com oito páginas destinadas ao cuidado da saúde física e mental. Assim, temas que abordam os cuidados com o corpo e a mente são transportados para um dizer jornalístico a partir de entrevistas com fontes das universidades gaúchas bem como de profissionais das mais diferentes especialidades da área da saúde.

Diferente do Eureka!, que busca matérias nas agências de notícias internacionais, o Vida é totalmente produzido por uma equipe de jornalistas da Zero Hora. São repórteres que coletam dados de temas universais, com fontes locais, aproximando o caderno de seus leitores. Como conseqüência direta desta característica, os leitores da capital gaúcha tem a oportunidade de se verem em fotografias que complementam os dizeres das matérias. Também podem identificar locais próximos a eles, como os parques da cidade, as academias, as opções gastronômicas saudáveis e outros lugares pertencentes a Porto Alegre e que fazem parte do cotidiano do suplemento.

Basicamente voltado para o combate dos males da sociedade moderna, o nome Vida significa a oportunidade de buscar através da leitura do caderno, melhores condições de saúde física e mental para enfrentar as moléstias, os modismos, os novos comportamentos e as novas exigências deste século.

No que diz respeito aos patrocinadores o Vida apresenta um conjunto de anunciantes ligados à área da saúde. A PUC/RS aparece entre consultórios médicos, clínicas médicas, serviços da área da medicina, entre outros. Inclusive, o caderno é o único dos três estudados que possui uma espécie de "classificados", denominado Guia de Saúde.

O planejamento gráfico é mais tradicional do que os outros dois, mas tem como força editorial, a presença da crônica do escritor Moacyr Scliar, membro da Academia Brasileira de Letras, que reforça a tematização do suplemento, pelo fato dele também ser médico e dedicar este espaço à assuntos ligados a saúde.

Muitos editores e repórteres já passaram pelo caderno Vida. Essa diversidade de perfil profissional não mudou, no entanto, as características textuais e gráficas do 
suplemento que mantém sua identidade a mais de doze anos. A circulação aos sábados, inclusive, é direcionada para uma leitura que motive seus leitores para saudáveis momentos de lazer no final de semana, uma das necessidades obrigatórias para uma vida plena e feliz, na fala do Vida.

\section{4 - Universidade do Eureka!, Vestibular e Vida}

Para entender o processo de visibilização das universidades, através do discurso jornalístico produzido nos suplementos, analisamos as marcas discursivas destes três encartes. É importante ressaltar, no entanto, que o discurso jornalístico está respaldado, no imaginário coletivo, por contratos de comunicação baseados em conceitos como credibilidade, isenção, imparcialidade e atualidade. Levando-se em consideração estas marcas do jornalismo, os critérios de noticiabilidade apresentados pelos suplementos também se valem destas características do campo jornalístico.

Isto posto, percebemos que o campo da universidade visibiliza-se na esfera midiática, nestes três suportes, por implicitação. Ou seja, os agentes sociais que visibilizam o campo da universidade são cientes de que, dificilmente, conseguiriam espaço para divulgar, todas as semanas, os acontecimentos do mundo da universidade, nos jornais de grande circulação, através de notícias que sinalizem, em parte, o seu mundo.

Existem revistas científicas especializadas para a divulgação de artigos e conhecimentos produzidos na Instituição. No entanto, estas divulgações são dirigidas para os seus pares. A grande massa, que os meios de comunicação social atingem, também devem ser informada. Como uma tendência da sociedade da informação, a segmentação das mensagens, proposta pelos cadernos, é uma possibilidade interessante. Afinal, eles tratam de encontrar meios de divulgação coerentes com a lógica da instituição que são da ordem do conhecimento, do ensino, da produção científica, enfim de todo o universo da instituição.

Os suplementos analisados articulam uma dessas possibilidades através de uma dupla implicitação, pois, da universidade. Após detectar as estratégias discursivas nos títulos, nos textos e nos elemento gráficos, que produzem discursos remissivos ao campo 
da universidade e, portanto, sentidos de seu mundo, explicitamos o que cada um deles articula como efeitos de significação

Com esta análise, queremos dizer que as estratégias discursivas do Eureka! com relação a visibilidade do campo da universidade são delicadas e sutis. Elas estão sempre construindo, no horizonte de seus temas, uma entrelinha aberta para o mundo da universidade. As matérias científicas têm dois níveis de produção de sentido. De um lado o explícito que é o assunto mesmo abordado: os temas que apresentam as descobertas de assuntos ligados aos campos da genética, da geologia, da nutrição entre outros, de grandes universidades internacionais ou até mesmo das universidades gaúchas como a Unisinos, PucRS, Ulbra, UFRGS etc.

De outro, o implícito que é a possibilidade de aplicar os raciocínios elaborados (por similaridade ou contraste) às nossas universidades. Entre o explícito e implícito há processos paralelos que são signficativos para o mundo das instituições universitárias. Com esta estratégia, a "química" entre o científico, a universidade e o prazer/facilidade de leitura do discurso midiático se completa.

Nas principais estratégias discursivas evidenciadas no suplemento, a pedagogização da informação através de infográficos, de matérias descritivas com imagens simbólicas e um planejamento gráfico facilitador da leitura transformam textos científico classificados como uma leitura "difícil”" em atraentes semantizações do saber.

Mas há outras possibilidades entre o explícito e o implícito que são evidenciadas no suplemento Vestibular. As reportagens que abordam os caminhos trilhados para a conquista do "mundo da universidade" procuram "fazer crer" a importância da transposição da barreira do concurso vestibular para viver o charme do mundo da universidade através de sofisticadas estratégias discursivas. O próprio funcionamento da ordem das matérias, privilegiando cases (histórias de vida) mostram o que existe "após" o vestibular.

A partir desta estratégia, o gênero feature atinge o máximo de eficiência. De modo analógico, as histórias de vida reveladas no caderno Vestibular aguçam a percepção em busca de subentendidos. Além disso, a descoberta das implicitações das matérias humanas 
propõem um sentimento de identificação. É na conjugação desse conjunto de matérias noticiosas que o caderno Vestibular vai "aliciando" os jovens para o desejo de fazer parte do mundo da universidade.

Esses espaços relacionais e negociais aparecem também em forma de discurso direto do campo da saúde no suplemento Vida. Ao abrir as páginas do caderno como lugar privilegiado de expressão do campo da saúde, o discurso do encarte não fecha sua frente em termos de significação, mas ao contrário, amplia e completa os sentidos nas bases formadoras deste campo e portanto da universidade. Afinal, toda a especialização deste campo tem, obviamente e necessariamente, uma origem: a universidade.

Podemos perceber que estas análises que procedemos da ordem da visibilização da pesquisa científica no Eureka!, da ordem de visibilização de um produto aliciador da universidade no Vestibular e da ordem de visibilização de uma autoridade especializada no Vida não são exclusivas entre si, pelo contrário, elas formam elos entre si, que denominamos como um discurso organizador da imagem da instituição universidade.

É possível afirmar que esses espaços "negociados" da universidade são produzidos pelo jornal Zero Hora, levando-se em consideração, evidentemente, a lógica econômica. Estas universidades são patrocinadoras destes espaços criados pelo jornal para organizar um conjunto de reportagens que nem sempre tem espaço no cotidiano do veículo. No entanto, o que realmente importa é que o campo da universidade se faz presentificado na cena midiática e, sobretudo, estrategicamente construído. Portanto, a partir de uma versão de universidade, que podemos chamar a "versão Eureka!", "a versão Vestibular" e a versão Vida", com todas as operações semânticas desenvolvidas por cada um destes suplementos.

\section{5 - Considerações finais}

A analise apresentada neste artigo, como já foi explicitado, é um recorte de um trabalho de tese que contextualiza as relações do campo da universidade com as mídias, tendo como pano de fundo a sociedade da informação. Este contexto refere-se a uma sociedade ambientada e estruturada pelas mídias, onde as instituições sociais 
tem status de existência, quando tem voz na esfera pública. Nesse sentido, a pesquisa tem como proposta teórico-metodológica, uma análise em nível macro analítico, das relações sociais entre esses dois campos e, investiga como estas relações são negociadas e tensionadas, em nível micro analítico, nas processualidades das práticas comunicativas, mas precisamente nos mecanismos de conversação entre universidade e sociedade através do discurso jornalístico.

Portanto, na proposta deste artigo, as relações entre universidade e mídia são percebidas através das discursividades produzidas em três suplementos editados pelo jornal Zero Hora, como uma série d elos que se encaixam e produzem significados, tomando como opção metodológica a proposição de que a estruturação dos vínculos entre os campos ocorrem no âmbito das manifestações discursivas.

\section{6 - Referências Bibliográficas}

FERRARETO, Maria Helena e SODRE, Munis . Técnica de Reportagem. Vozes. Rio de Janeiro 1995

NUNES. Augusto. Manual de Redação do jornal Zero Hora. L\&PM Editora. Porto Alegre.1994.

RODRIGUES, Adriano. Experiência, modernidade e campo dos media. IN: Reflexões sobre o mundo contemporâneo. R. N. Monteiro de Santana (org). Rio de Janeiro: Revan: Teresina. PI: Universidade Federal do Piauí.20oo. 